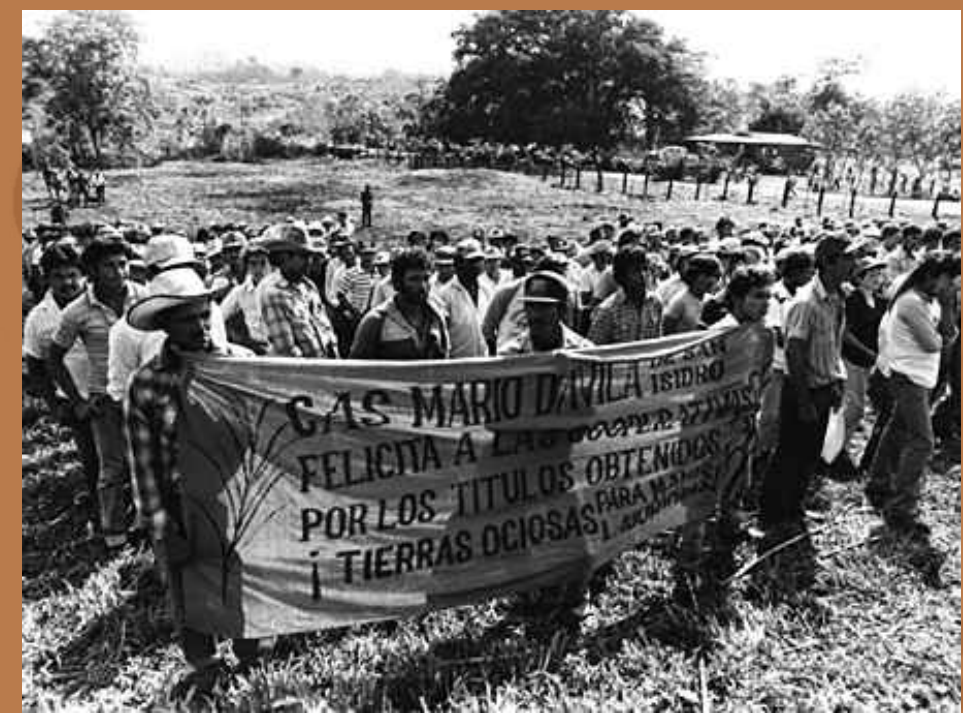

Portada: Reforma agraria en Nicaragua.

Foto: Internet

Frontera Agrícola, Movimientos campesinos y Pueblos Indigenas del norte de Nicaragua $(1980-2019)$

"De los milpas y chilotes a los auto-convocados"

Pueblo, cultura e identidad 


\title{
Frontera Agrícola, Movimientos campesinos y Pueblos Indí- genas del norte de Nicaragua (1980-2019)
}

\author{
"De los milpas y chilotes a los auto-convocados"
}

Agricultural Frontier, Peasant Movements and Indigenous Peoples of Northern Nicaragua (1980-2019) "De los milpas y chilotes a los auto-convocados"

\author{
Uwe Paul Cruz Olivas \\ Historiador y Arqueólogo \\ Fundación Científica Cultural Ulúa Matagalpa \\ ID Orcid: https://orcid.org/0000-0001-9925-1640 \\ uwepaulcruz@gmail.com
}

\section{Resumen}

En el presente artículo analizare los movimientos campesinos e indígenas de los municipios de Wiwili y Bocay en los últimos 40 años, las fuentes fueron obtenidas a través de cinco años de intenso estudio arqueológico, histórico, lingüístico, antropológico y sociológico en el departamento de Jinotega. Se trabajó con documentación histórica de los municipios en mención, se implementaron los métodos y técnicas etnográficas y etnológicas para el registro de testimonios de líderes comunitarios que formaron parte de la contrarrevolución y el Ejército Popular Sandinista (1981-1990). El énfasis esta puesto en los cambios históricos y estratégicos que vienen sufriendo los campesinos e indígenas desde los años de la guerra de1980, su transformación en la lucha por el acceso a la tierra en la década de 1990, hasta la creación de las regiones especiales llamadas Wangki Wihta Bukawas ubicados en el área núcleo de la Reserva de la Biosfera de Bosawas y compuesta por tres territorios miskitus como son: Miskitu Kipla Sait Tasbaika, Miskitu Indian Tasbaika Kum y Miskitu Lilamni Tasbaika Kum y un territorio Mayangna Sauni Bu, todos conocidos como Gobierno Territorial Indígena (GTI) restituido por el actual gobierno sandinista en el año 2008. En el departamento encontramos una dinámica multicultural poca estudiada por los antropólogos nicaragüenses, particularmente en los municipios de Wiwili y Bocay regiones severamente afectada y devastada por los intensos combates que se desarrollaron en dicho territorio, desde la gesta libertaria de Augusto C. Sandino hasta la guerra de 1980 y durante la posguerra.

Palabras claves: Conflicto Armado, Movimientos Campesinos, Frontera Agrícola y Pueblos Indígenas en el norte de Jinotega.

\section{Abstract}

In this article I will analyze the peasant and indigenous movements of the municipalities of Wiwili and Bocay in the last 40 years, the sources were obtained through five years of intense archaeological, historical, linguistic, anthropological and sociological study in the department of Jinotega. We worked with historical documentation of the municipalities in question, the ethnographic and ethnological methods and techniques were implemented for the registration of testimonies of community leaders who were part of the counterrevolution and the Sandinista Popular Army (1981-1990). The emphasis is placed on the historical and strategic changes that peasants and indigenous people have been suffering since the 1980s, their transformation in the struggle for access to land in the 1990s, until 
the creation of special regions called Wangki Wihta Bukawas located in the core area of the Bosawas Biosphere Reserve and composed of three Miskitus territories such as: Miskitu Kipla Sait Tasbaika, Miskitu Indian Tasbaika Kum and Miskitu Lilamni Tasbaika Kum and a Mayangna Sauni Bu territory, all known as Government Indigenous Territorial (GTI) restored by the current Sandinista government in 2008. In the department we find a multicultural dynamic little studied by Nicaraguan anthropologists, particularly in the municipalities of Wiwili and Bocay regions severely affected and devastated by the intense fighting that developed in that territory, from the libertarian deed of Augusto C. Sandino hast to the war of 1980 and during the postwar period.

Keywords: Armed Conflict, Peasant Movements, Agricultural Frontier and Indigenous Peoples in northern Jinotega

\section{Introducción}

La historia de Nicaragua es compleja y contradictoria hasta cierto punto, como sabemos, el Frente Sandinista de Liberación Nacional (FSLN) fue la organización guerrillera que llego al poder político del país. A raíz del derrocamiento de una de las dictaduras familiar más sangrientas y genocida de América Latina, la que contaba con el amplio apoyo del gobierno de los EEUU desde mediados del siglo XX. Con el triunfo de la revolución nicaragüense, fue el segundo revés geopolítico que sufriría el imperialismo norteamericano en su mal llamado "patio trasero" o República Bananera de Centroamérica.

La Revolución Popular Sandinista empezó el 19 de julio de 1979, fecha histórica celebrada por cientos de miles de nicaragüenses, unificados bajo los principios revolucionarios del anti imperialismo, anti-intervencionismo y los valores culturales propios de nuestra cultura política. Principios sociales heredados de la gesta heroica del General Augusto Nicolás Calderón Sandino quien fue traicionado, torturado y asesinado por la Guardia Nacional luego de haber pactado los acuerdos de paz, más importantes de la historia Nicaragua. Dentro de las prioridades de la naciente revolución estaba: erradicar el analfabetismo, desconocer los tratados "Chamorro-Bryan", mejorar el acceso a la tierra a través de confiscación de las propiedades de las familias burguesas y oligarcas afines a la dictadura somocista, para redistribuirlas a los campesinos y obreros sin tierras.
Las primeras medidas tuvieron como objetivos erradicar el analfabetismo en toda Nicaragua, la segunda tuvo un sentido geopolítico al desconocer un tratado político con los EEUU que le prohíbe al país la construcción de un canal interoceánico en un periodo de 100 años y la tercera medida estaba orientada a los grandes terratenientes vinculados a la familia Somoza, quienes controlaban una quinta parte de las tierras cultivables principalmente en la zona del pacifico y centro norte de Nicaragua (Close, 2005, p. 44). Particularmente, estas fueron las bases del reparto agrario sandinista para la organización estatal de la producción y la reorganización de las actividades económicas a través de las cooperativas campesinas, las cuales en su mayoría se encontraban en los territorios de las comunidades indígenas del pacifico centro y norte.

La implementación de la reforma agraria durante el periodo revolucionario amplio el acceso a la tierra a los campesinos e indígenas empobrecidos en los departamentos de Matagalpa y Jinotega, por el sistema agroexportador del régimen somocista. Con la implementación de las innovaciones agrarias la revolución sandinista en los primeros años mejoro el sistema de crédito y democratizó la distribución de tierras. Sin embargo, para 1981 se formó en la zona fronteriza con Honduras la agrupación de mercenarios y ex guardias somocistas autodenominados "Los Milpas" con 600 hombres que rechazaban la victoria popular de las milicias sandinistas. Estos paramilitares armados 
contaron con el apoyo logístico y financiero de la agencia de inteligencia CIA de los EEUU, quienes desde territorio hondureño venían realizando trabajos subversivos, hasta el nacimiento del "FDN" y llegar a fundar a la contrarrevolución la que para 1986 llego a tener 17,032, y en 1987, un año después de la reforma agraria ya sumaban 17,500 hombres en armas en la Contra (Morales, 1989; Núñez y Cardenal, 1992).

Así fue que Ronal Reagan les imponía un embargo comercial y una guerra de más de nueve años a los nicaragüenses, con el claro objetivo de desgastar a la población civil, ejército y las milicias revolucionarias para exterminar de una vez por toda con el "comunismo" en Centroamérica. El gobierno sandinista en medio de la desgastante guerra y bloqueo instauró una serie de políticas de comercialización y distribución de los productos agrícolas, regulando los precios de los granos para tener control de los principales granos básicos que se producía en el país, a través de la Empresa Nacional de Alimentos Básicos (ENABAS). Las medidas fueron tomadas bajo un contexto de guerra impuesta que de cierta manera atentaba contra los comerciantes e intermediarios acostumbrados a especular con el valor agregado de los productos agrícolas. Sin embargo, la revolución nicaragüense en medio de sus aciertos y desaciertos estableció los nuevos principios y reglamentos de la nueva institucionalidad del país, construyendo un nuevo estado soberano y promulgo una nueva constitución en 1987 definiendo la autonomía de la Costa Caribe nicaragüense.

\section{Discusión y análisis}

Pese a las dificultades que atravesaba la revolución nicaragüense la implementación de la reforma agraria fue uno de los grandes logros, como la lucha contra el analfabetismo, la educación bilingüe para el Caribe y la documentación de las lenguas Rama, Ulwa, Miskitu y Mayangna con el reconocimiento de sus territorios ancestrales y cosmovisión. Según un estudio del Banco Mundial citado por ACNUR:

Las políticas de reforma agraria iniciadas en 1980 han sido exitosas ya que logro invertir el patrón de tenencia de la tierra de los años setenta, haciéndolo uno de los sistemas más equitativos en toda América Latina, en el cual el 75\% de la tierra de uso agrícola pertenecía a pequeños y medianos productores (ACNUR, 1991, p.17).

Las políticas de reforma agraria iniciadas en 1980 han sido exitosas ya que logro invertir el patrón de tenencia de la tierra de los años setenta, haciéndolo uno de los sistemas más equitativos en toda América Latina, en el cual el 75\% de la tierra de uso agrícola pertenecía a pequeños y medianos productores (ACNUR, 1991, p.17).

Yo me movilizaba con el comandante Tigrillo y Rubén, con el fundamos los Chilotes tiernos, las principales rutas que utilizamos fueron La Pita del Carmen, Pantasma, La gusanera, El Caño de la Cruz, La Marañosa hasta el rio Coco. Teníamos orientaciones claras de buscar armas, conseguir pertrechos militares, avituallamientos, red de colaboradores y no permitimos que los alfabetizadores llegaran a las comunidades donde patrullábamos y le dábamos persecución a las casas de habitación que alojaban a los jóvenes. En varias zonas tuvimos conflictos o tiroteos como en una finca en el Caño de la Cruz (2018).

Así fue que en varias ocasiones la contrarrevolución imponía miedo y no respeto entre los campesinos e indígenas del norte de Jinotega, pese a dicha realidad, entre chantajes y voluntad las filas del FDN se seguía alimentando de campesinos que en muchos casos no sabían porque en realidad luchaban. Para 1981 el gobierno sandinista enfrentaba ataques de los contrarrevolucionarios desde la región nor-oriental del departamento de Jinotega, el que se convirtió en un escenario principal de los conflictos armados. El FSLN, con el fin de evitar que estas comunidades pudieran servir de apoyo logístico para los contrarrevolucionarios y no afectar a poblaciones indígenas en los conflictos, decidió evacuar a más de 8,500 personas de las comunidades del Rio Coco y Bocay y ubicarlos en asentamientos improvisados, garantizando condiciones para que las familias se incorporasen en la producción agrícola y pecuaria. Para el caso específico de Uluaskin en Wiwili y Amak, se desplazaron a la población a los departa- mentos de Jinotega y Matagalpa 
principalmente. Las comunidades de rio Coco abajo, serían ubicadas en lo que fue conocido como Tasba Pri (Tierra Libre). La operación de desalojo no fue anunciada públicamente para no alertar a las fuerzas contrarrevolucionarias, por lo que la población de las comunidades fue avisada con poca anticipación. En las comunidades, se cortaron los árboles frutales y se mató parte del ganado para asegurar que los Contras no pudieran hacer uso de estos. Uno de los hechos en el inicio del desplazamiento que afectó a la población, fue el trágico accidente de un helicóptero por desperfectos mecánicos, que transportaba a mujeres y niños desde la comunidad de San Andrés a la Comunidad de Ayapal. Este incidente se cobró la vida de 75 niños y niñas, juntos con ocho mujeres adultas.

La Navidad Roja fue punto de mira mediático y se acusó al Frente Sandinista de violar los derechos humanos de la población mískitu. Hubo serios desacuerdos y cruce de acusaciones con el movimiento indígena de Costa Caribe en aquella época denominado MISURASATA. Posteriormente la Organización de Estados Americanos reconoció el esfuerzo del Gobierno en garantizar condiciones para la población traslada. ra que todavía los mayores obstáculos que confronta la población miskitu se deben a su falta de participación en las decisiones que las afectan, resultado a la vez de la recíproca desconfianza que existe entre esa población y el Gobierno, todo lo cual contribuye a acentuar las tensiones y dificultades existentes (CIDH-OEA, 1983).

La guerra poco a poco iba desgastando la frágil economía agroexportadora de Nicaragua y golpeando contundentemente a los civiles por el racionamiento de los alimentos, escases de utensilios personales, como pasta, máquinas de afeitar y otros productos importados, mientras se racionaba el arroz, aceite y azúcar.

Los Contras en su mayoría eran campesinos de la frontera agrícola, en algunos casos familias productoras que dependían del mercado internacional para vender sus productos, pero al mismo tiempo, producían todos sus alimentos para la subsistencia y el excedente usado para la venta al mercado, así formaron comunidades con cierta movilidad económica y social, con mínima relación con el Estado, tal es el caso de la comarca Runflin en Bocay, donde el líder comunitario José Sixto González Hernández (2015) quien dijo que:

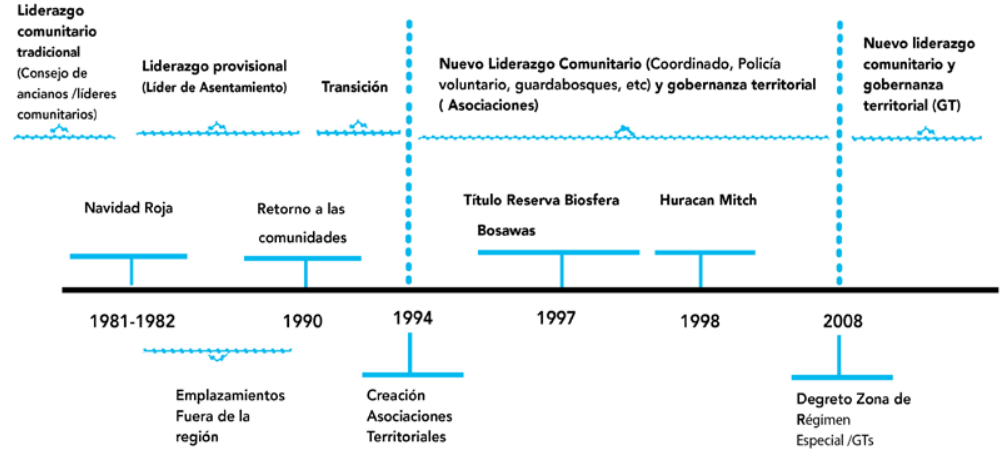

La Comisión reconoce los esfuerzos del Gobierno de Nicaragua en suministrar servicios en materia de sanidad, educación, y bienestar tanto en los nuevos asentamientos como en las aldeas del norte del Departamento de Zelaya habitadas por mískitus (aunque, hasta ahora, no ha podido superar los relativos a suministrar una adecuada alimentación). Con todo, la Comisión conside-
Yo fui comando de la contra, mi alias era "Rafael", así me conocen aquí. Anduve en las tropas de varios comandantes entre ellos, el difunto comandante "Masaya" y "Tiro al Blanco", "Tigrillo", con "Solín Chele", "inventarios", "Iván Perdido" y "Dimas". Recuerdo las operaciones de Bocay de 1987, fueron operaciones que hicimos viniendo de Honduras cuando atacamos el $1^{\circ}$ de junio al EPS. Al mando veníamos de los comandantes "Toño" y "Gato 31", éramos una tropa de 800 hombres en una fuerza que se denominaba Juan Castro en honor a un caído. En esos combates me pegaron un tiro en el pie derecho y herido puede salir hasta Honduras, ahora estamos en paz y defendemos esta paz (Rizo, 2015).

En Runflin el espectro de la guerra se puede percibir en las evidencias de sus montañas, donde todavía se 
pueden encontrar antiguas cantimploras y latas de sardinas que fueron utilizadas por las columnas del extinto EPS, la comarca fue uno de los antiguos refugios primordiales para la Contras donde fácilmente podían continuar con su ruta hacia el norte en dirección a la comunidad de Olaskin, Olaskinon y llegar así al territorio indígena de Uluaskin, donde según líder indígena Ambrosio Ocampo (2018) dice que:

Nuestros líderes no hablaban muy bien el hispai o español y por nuestros años de abandono de nuestros territorios no conocíamos muy bien lo que pasaba en Managua y menos luego cuando nos invadieron los rearmados, quienes venían exigiendo tierras, mujeres y apoyo militar para derrocar el comunismo sandinista (2018).

Entre 1987 y 1988 el gobierno revolucionario implementó el Plan de Ajuste que residió en una reforma monetaria, que consistía en devaluar el córdoba respecto al dólar en una relación del 80 a 1 , esta difícil situación aumento el descontento de un amplio sector de la población campesina y urbana quienes históricamente han tenido dependencia y seguridad en la primera moneda de intercambio internacional. Pero no doblegaba a los sandinistas revolucionarios, que mantuvieron un gobierno bajo un embargo económico, carencias de productos y una alta inflación de una economía de guerra. Las medidas del Plan Ajuste consistieron en ajuste salarial, centralismo político, reestructuración económica, crediticia, renegociación de las deudas bancarías, la liberalización de los precios y salarios, reducción en el presupuesto de salud y educación.

Para 1989 el empleo público disminuyó, afectando a 50, 000 mil personas, mientras la tasa de desempleo rondaba el 28\% (Vilas, 1993). Las carencias y dificultades de los nicaragüenses se sentían en las necesidades básicas de subsistencia, tras décadas de dependencia comercial con los EEUU, quien termina imponiendo un embargo económico desde 1983 y una guerra al país, que le costó más de 50,000 vidas humanas y más de 16, 000 víctimas de guerra de ambos bandos. Para las elecciones de 1990 la crisis económica y política en el país era muy profunda a causa de la imposición bélica, con la victoria electoral de Violeta Barrios de Chamorro los movilizados campesinos de la Contra se lanzarían sobre los territorios de las comunidades indígenas desalojadas por el conflicto armado, de esta manera muchas familias campesinas se asentaron en las antiguas aldeas indígenas asentadas en las riveras del rio Ayapal y Runflin.

Según Rizo (2004) el sujeto de la frontera agrícola tiene como origen un campesinado antiguo generacional que en tiempos atrás fueron familias indígenas desplazadas por otros blancos y con el tiempo y la presión de la modernidad intento desaparecer por arte de magia, esas identidades culturales subsisten hasta la actualidad. Así mismo, el denominado campesino de la frontera agrícola es un sujeto social con una identidad cultural propia, enriquecida con el mito dominante del Estado Nación, que se impone a las otras formas de organización social y cultural de la tierra.

Así fue que cuando los pueblos indígenas Miskitu y Mayangna retornaron a sus antiguos territorios ancestrales, se van a encontrar con el otro, es decir el campesino de la frontera agrícola que se asentó en las antiguas aldeas indígenas. Cercando su "propiedad privada" la cual el decidió hasta donde y como seria, así nació el conflicto ya no armado, pero si político e ideológico donde el mestizo es el heredero de la cultura Nacional nicaragüense, impone un modelo de producción capitalista y neoliberal. El gobierno de Chamorro anunció una propuesta de ley relativa a la revisión de las confiscaciones sandinistas, buscando beneficiar a todas las familias vinculadas a los Somoza y aceptores burgueses que se vieron afectados durante el gobierno revolucionario. En los hechos se trató de la primera contra reforma agraria de corte netamente neoliberal que se desarrollaría en el país, otra transformación fue la libertad comercial para los campesinos y productores para que ellos decidieron a quien venderle sus productos, al mismo tiempo, se privatizaron todas las empresas del Estado heredadas del gobierno revolucionario (INCEP, 1994).

Eliminando las políticas de control estatal y de carácter distributivo e impone el libre mercado en un sentido neoliberal globalizado, lo que incluía las empresas nacionales y los intentos por destru- 
ir el sandinismo desde todos los focos y campos ideológico, esto provoco una división entre los dirigentes y comandantes de la revolución quienes muchos optaron por formar el Movimiento Renovador Sandinista (MRS) hasta instaurar una democracia desigual netamente procedimental y electoral. Como muestra del beneplácito el gobierno de los EEUU aprobó inmediatamente un paquete de ayuda económico de $300 \$$ millones de dólares, mismos que fueron condicionados por los norteamericanos al realizar un desembolso de $147 \$$ millones, esta acción complico más al gobierno neoliberal, pues era en los meses donde más se necesitaban fondos para la reducción del Ejército Popular Sandinista (EPS) y al Ministerio del Interior (MINT) al que se le obligó a retirar a una buena parte de sus miembros, por el otro lado, se desmovilizando a 22, 413 combatientes de la Contrarrevolución (UNO,1990 p.8). Mismos que fueron patrocinados por las agencias de seguridad de los EEUU que operaban ilegalmente el conflicto armado desde territorio hondureño.

Así mismo, los EEUU impuso a la Comisión Internacional de Apoyo y Verificación de la Organización de Estados Americanos (CIAV-OEA) quien debía de administrar los 300 millones de dólares otorgados en préstamos de los cuales, sólo un $10 \%$ se destinó a la desmovilización de los Contras y los restantes $90 \%$ iban destinados al gobierno neoliberal de Violeta Barrios de Chamorro.

Para 1990 existían 60, 000 demandantes de tierras y más 2,000, 000 millones de familias campesinas e indígenas afectadas por el problema de la propiedad, además de más de 6,000 mil ex propietarios que exigían la devolución de las tierras confiscadas por la revolución sandinista. Así fue que el gobierno neoliberal vendió las Corporaciones Nacionales del Sector Publico (CORNAP), como un mecanismo de privatización y devolución de las propiedades del Área de Propiedad del Pueblo (APP), que representaba para 1990 aproximadamente el 40\% del producto Interno Bruto (PIB) de Nicaragua y empleaba a más de 78, 000 trabajadores, sin embargo, el gobierno neoliberal no le interesaba el pueblo empobrecido y no tardo en desmembrar y privatizar las tierras a beneficios de los mismos grupos de poder excluyentes (Rueda, 2019). Al mismo tiempo, el gobierno condonaría de manera ilegal la deuda de 16, 000,000 millones de dólares que el Tribunal Internacional de Justicia (TIJ) de la Haya en Holanda falló a favor de Nicaragua, responsabilizando a los EEUU de violar el derecho internacional al apoyar a la oposición armada y ser el principal promotor de la guerra en el país. Sin embargo, con la condonación ilícita de la deuda histórica, las clases políticas tradicionales de familias liberales y conservadoras, oligarcas y burgueses se repartieron jugosos prestamos económicos y rápidamente se volvieron a enriquecer a merced de las inmensas mayorías de nicaragüenses empobrecidas en el campo y las ciudades.

Con el mismo entreguismo político, gobernarían Nicaragua en medio de las adversidades económicas y sociales en una sociedad que venía de derrocar una de las dictaduras familiares más sangrientas y genocidas de Latinoamérica apoyadas por Washington, sumándole una guerra contrarrevolucionaria de más de nueve años apoyada y financiada por el mismo imperio. Así fue, que la clase política tradicional empujarían a millones de obreros, campesinos e indígenas a la miseria y pobreza extrema, sin mencionar los miles de personas lisiadas y víctimas de guerra que nunca fueron atendidos por el gobierno y menos que tuvieran los beneficios de la supuesta ayuda "humanitaria" norteamericana que tampoco llegó a los campesinos e indígenas de la Contra.

Así fue que el Estado nicaragüense dejaría de ser el principal empleador en el país y se convertiría en el principal consumidor de los contribuyentes, para 1990 proporciono a penas 285, 000 empleos y al final del gobierno de Violeta Barrios de Chamorro en 1996 alcanzaría tan sólo 77,000 (Monroy, 2001). Al mismo tiempo, el gobierno de transición promovió las importaciones, las disminuciones de los aranceles, la libertad cambiaria, la eliminación de subsidios para las clases pobres, pero no para la burguesía y oligarquía quienes pagarían ridículas tasas de impuesto en las importaciones de autos y otros artículos, además de las exoneraciones, los créditos y las tasas bajas de interés, disminuirían el papel del Estado en la economía nacional y privatizarán sus activos a corporaciones internacionales, sociedades anónimas y grupos de poder tradicional, pasando a ser el sector privado el único motor de la incipiente economía nacional (Arancibia, 1993). De esta manera, la legislación nicaragüense 
aprobaría la inversión extranjera instaurando las maquilas y las zonas francas, donde la explotación capitalista se intensificaba, sin embargo, la necesidad del pueblo forzó a miles de mujeres y madres solteras a buscar empleos con salarios fijos. Con la implementación del neoliberalismo nunca se llegó a cumplir las promesas electorales que llevaron al poder político a Violeta Barrios de Chamorro, pues la recuperación económica de Nicaragua nunca llegó y a partir de 1990 a 1992 la combinación criminal del desempleo, subempleo y la pobreza extrema cubrió a más de dos tercios de la población económicamente activa (Vilas, 1994, p.260).

Durante los años de posguerra, los ricos disminuían en número y aumentaban en riquezas, mientras los pobres aumentaban en número y disminuían en riquezas, increíblemente la población empobreció más rápidamente, incluso más que durante los duros años de la guerra impuesta por EEUU. La única diferencia muy marcada estaba en el discurso de la "democracia" desigual promovida por el gobierno neoliberal (Rueda, 2019). Las respuestas populares contra las políticas neoliberales de Barrios no se hicieron esperar y cientos de personas empezaron a organizar independientemente o dentro del FSLN para crear los primeros "tranques" termino popular para referirse al cierre de las principales vías de comunicación, una estrategia urbana nueva en el país que resultaba más dañina para la economía frágil y condicionada de Nicaragua.

Los tranques fueron organizados en buena manera por los sandinistas quienes se encontraban completamente en desacuerdo con las políticas neoliberales de Violeta Barrios de Chamorro quien no sólo había condonado ilegalmente una deuda de más de 16, 000,000 millones de dólares, sino que acepto una ayuda condicionada de EEUU que el pueblo nunca recibió por la amplia corrupción del gobierno neoliberal. A estas acciones le siguieron múltiples huelgas sindicales entre ellos los gremios de maestros y enfermeras, además de huelgas de hambres de militares retirados y las constantes luchas estudiantiles de más de dos meses de huelga en 1992 contra los recortes inconstitucionales del presupuesto Universitario conocido popularmente como el 6\%. Para septiembre de 1993 tuvo lugar el paro nacional de trasportistas que paralizó al país por varios días, estos tranques desestabilizaban la macro y micro economía, bajo este contexto el gobierno neoliberal desesperado trato de obtener fondos frescos, a través de la venta de empresas y propiedades estatales de la CORNAP, desmantelando gran parte de los bienes que tenía el Estado. Al mismo tiempo, los políticos le apostaron al crecimiento agrícola y ganadero del país con la venta de las propiedades y de empresas estatales, pues la tierra podía entregársele a los ex comandos para hacerlas producir y con ello se dinamizaría la economía nacional y abastecería el mercado interno y externo.

Omitiendo el complejo problema de la propiedad privada, pues a la fecha ya habían más de 6,000 reclamos que exigían la restitución de las propiedades confiscadas a las familias afectadas (Enríquez, 1993). Dentro las contradicciones generales estaban más de 800 somocistas empecinados en destruir al FSLN, revertir las trasformaciones agrarias y urbanas contra 30,000 familias beneficiadas, entre ellas tenemos 120,000 mil favorecidas por la reforma agraria y más de 60,000 desmovilizados de la Contra, cuyo nombre oficial después de la guerra fue (RN). Además, de los retirados del EPS y trabajadores participantes del proceso de privatización, se hacían unos 2,000,000 millones de personas involucradas en los problemas de titulación, es decir casi de la mitad de la población nicaragüense (Rueda, 2019).

A partir de la venta ilícita de las propiedades, empresas del estado y la institucionalización del neoliberalismo aparece un nuevo actor social sediento de tierras actas para el cultivo y bajo costos, este sujeto serán los extranjeros inversionistas quienes fueron beneficiados con las concesiones extractivitas. Como la licencia a la empresa minera norteamericana "Gold Neptune Company" a quien se le concedió explotar las regiones auríferas más importantes del caribe norte.

Al mismo tiempo, se le otorgo a "Atlantic Timbres Coorporation" (ATMICO) unas 8, 333 hectáreas de bosques vírgenes en el caribe sur y posteriormente le cedieron 55,000 hectáreas de selva tropical húmeda para la explotación de recursos madereros, sin la indemnización del Estado y menos de las comunidades del caribe sur. Según don Victorino Benavidez (2016) líder campesino de la comarca de Runflin, dice que:

A nosotros los fundadores de la Contra en Bocay Jinotega, el gobierno de doña Violeta Barrios de Cham- 
orro no nos entregó lo que prometió, ni tierras, ni semillas, ni viviendas, ni animales y menos herramientas para el trabajo de la agricultura (2016) El testimonio del líder es contundente cuando habla indignado sobre las promesas no cumplidas por la administración de Barrios, quien lo dejo en la eterna espera, dejando así a miles de familias campesinas indefensas y condenadas a la pobreza extrema hasta nuestros días. Según Ruedas (2019) eran alrededor de 22, 413 comando de la (RN), más 72, 000 del EPS y unos 5, 100 del MINT, la mayoría de los Contra querían regresar al campo, pero no tuvieron los apoyos suficientes por parte de los EEUU quien una vez entregada las armas corto todo apoyo o financiamiento a los campesinos (p.10). Bajo este contexto fue que los excombatientes del norte de Jinotega tuvieron como única solución otra vez el rearme campesino ante las políticas neoliberales del gobierno de Violeta Barrios de Chamorro.

Reclamando tierras para 5,000 desmovilizados y colaboradores de la Resistencia Nicaragüense, los cuales ya no era útil a las políticas hegemónicas del imperialismo norteamericano y menos para la clase política criolla del país. De esta manera fue que empezaron a invadir los campesinos de la frontera agrícola la reserva natural Bosawas alternando las relaciones sociales con los pueblos indígenas Miskitu y Mayangnas quienes fueron reubicados en sus antiguos pueblos.

Durante los primeros años de la posguerra, la amplia demanda de la tierra demostró la falta de planificación del gobierno para atender a este sector fundamental de la sociedad nicaragüense, así ante la imposibilidad de entregar las regiones tradicionales de Matagalpa y Jinotega de producción, se promovió el avance de la frontera agrícola a las regiones más lejanas como el caso de las comunidades indígenas de Wiwili, Bocay y otras regiones del Caribe nicaragüense.

Los ataques a fincas ganaderas y cafetaleras no se hacían esperar en los municipios de Wiwili y Bocay, luego fueron los poblados, los pequeños centros de policía y los puestos de mandos del ejército, cierre de carreteras, tomas de iglesias entre ellas la catedral de Managua y hasta la sede de diplomática de la Organización de Estados Americanos (OEA), la CIAV-OEA, la embajada venezolana, la colombiana e incluso la de Nicaragua en Costa Rica. Particularmente los municipios del norte de Jinotega seguían siendo los escenarios más crudos de revueltas de campesinos e indígenas. Para complicar más el asunto, el gobierno neoliberal decidió en 1993 firmar un acuerdo entre el gobierno y el Fondo Monetario Internacional (FMI), las que incluyó nuevas políticas restrictivas o, mejor dicho, un nuevo paquetazo neoliberal.

Según Ruedas (2019) para 1994 el 66\% de los nicaragüenses estaban en desempleo y un 53\% estaba fuera del mercado de trabajo, sumado a que no había recursos para la inserción de excombatientes de ambos lados, el país se encontraba sumido en la pobreza extrema y las desigualdades sociales y políticas se hacían sentir, este hecho convirtió a Nicaragua en el segundo país más pobre del hemisferio, mientras el gobierno presumía de haber cumplido con todos sus compromisos internacionales para optar al préstamo. Mientras esto ocurría en Managua el ejército informó que entre enero y septiembre había consignado 583 actividades relacionadas con el rearme en los municipios del norte de Jinotega, las estadísticas eran aterradoras puesto que habían más de 50 asesinatos a familias campesinas e indígenas, 45 secuestros, 48 asaltos en las carreteras, 31 incendio de vehículos, 92 combates entre los rearmados y la fuerza del orden público que dejaron saldos de 66 muertos, 75 heridos y 5 capturados. Además, se logró desarticular en combate a 85 bandas y se desmovilizaron 5 agrupaciones de rearmadas Miskitu (p. 11).

En 1995 la Policía Nacional había investigado 48,737 delitos, si nos ponemos a comparar con los delitos ocurridos en 1985 en el fragor de la guerra habían sido 15,189 , en pocas palabras podemos afirmar que durante la posguerra fue en muchos sentidos tan violenta como la guerra de 1980. Para el 20 de enero de 1992 y febrero de 1995, por medio de la Brigada Especial de Desarme (BED), desmovilizó a 131 grupos y 24, 419 hombres (Arévalo, 2007).

El rearme fue el resultado de un proceso organizativo de un sector importante de excombatientes de origen indígena y campesinos mestizos que ejercieron presión por medio de las armas para presionar entregar tierras, sin embargo, durante los primeros años de la posguerra la gran cantidad de demanda por el ac- 
ceso a la tierra demostró la incapacidad del entonces gobierno de resolver sus promesas. Como resultado de lo narrado, en el corto y mediano plazo, en los municipios de Wiwili y Bocay las principales zonas de bosque se fueron convirtiendo en áreas de agricultura descontrolada y no organizada, los campesinos se fueron extendiendo en detrimento del medio ambiente, empujando cada vez más a las profundidades de la montaña a los indígenas Mayangna y Miskitu quienes no luchaban por un parcela de tierra de cultivo, sino por la reivindicación histórica de sus territorios ancestrales.

No obstante, paralelamente a la lucha de reivindicación territorial indígena en las regiones del alto y bajo Wangki, hay que sumarle las fuertes presiones de los campesinos rearmados de la frontera agrícola de los municipios de Wiwili y Bocay para obtener tierras legales. A pesar de la lucha justa por conseguir un título real, el gobierno de turno se dedicó a deslegitimizar la lucha, por el interés de conceder concesiones mineras a empresas norteamericanas. Estas acciones provocaron el surgimiento nuevas batallas del campesinado e indígenas sin tierra contra las políticas extractivita neoliberales del gobierno de Barrios de Chamorro, naciendo nuevos movimientos sociales pro ambientales, tanto en el campo como en la ciudad.

Los últimos años de la administración de Violeta Barrios de Chamorro fueron los más críticos para los campesinos e indígenas quienes no sabían realmente lo que estaba pasando en el país y menos porque el gobierno nunca cumplió con sus promesas electorales. Lo cierto del asunto, es que los paquetazos neoliberales nunca fueron las mejores acciones políticas y económicas para el pueblo empobrecido de Nicaragua, si para las corporaciones norteamericanas y el COSEP quienes continuaron defendiendo aún gobierno que velaba por los intereses de las minorías elitistas. Mientras continuaba empobreciendo a millones de ciudadanos en el campo y la ciudad, sin mencionar que las familias víctimas de la guerra eran objeto de desprecio social por la burguesía, las elites gobernantes y por el mismo EEUU quien sólo utilizó a los Contra como carne de cañón.

\section{Conclusión}

La frontera agrícola, los movimientos campesinos e indígenas del norte de Nicaragua sigue siendo un tema de interés nacional, debido a que en los primeros 20 años se ha demostrado que la rebeldía sigue siendo uno de sus principales elementos, como el profundo deseo de autonomía no solo del mercado, sino del acceso a la tierra, es ahí uno de los principales choques con los grupos indígenas protectores de los recursos naturales de sus tierras. Así en los años noventa vemos que los campesinos exigían promesas nunca cumplidas por los gobiernos neoliberales privatizadores de la salud, educación y de las Corporaciones Nacionales del Sector Publico CORNAP, como un mecanismo de privatización y devolución de las propiedades del Área de Propiedad del Pueblo (APP), que representaba para 1990 aproximadamente el 40\% del producto Interno Bruto (PIB) de Nicaragua y empleaba a más de 78, 000 trabajadores, sin embargo, el gobierno neoliberal no le interesaba el pueblo empobrecido y no tardo en desmembrar y privatizar las tierras a beneficios de los mismos grupos de poder excluyentes.

Bajo este contexto se crearon los rearmados y los recontra contras para presionar de algún modo a los gobiernos de turno, sin embargo, estos fueron ignorados por completo por el gobierno neoliberal de doña Violeta Barrios de Chamorro dejaría de ser el principal empleador en el país y se convertiría en el principal consumidor de los contribuyentes, para 1990 proporciono a penas 285, 000 empleos y al final del gobierno de Violeta Barrios de Chamorro en 1996 alcanzaría tan sólo 77,000. Al mismo tiempo, el gobierno de transición promovió las importaciones, las disminuciones de los aranceles, la libertad cambiaria, la eliminación de subsidios para las clases pobres, pero no para la burguesía y oligarquía quienes pagarían ridículas tasas de impuesto en las importaciones de autos y otros artículos, además de las exoneraciones, los créditos y las tasas bajas de interés, disminuirían el papel del Estado en la economía nacional y privatizarán sus activos a corporaciones internacionales, sociedades anónimas y grupos de poder tradicional, pasando a ser el sector privado el único motor de la incipiente economía nacional. 


\section{Bibliográfica}

ACNUR. (1991). Evaluación del proceso de reinserción de la población cirefca en las regiones central y norte de Nicaragua.

AFP. (30 de marzo de 2016). FMI abandonará Nicaragua debido a su estabilidad económica. Empresa \& Managment. Recuperado de www.estrategiaynegocios.net/ lasclavesdeldia/944851-330/ fmi-abandonar\%C3\%A1-nicaragua-debidoa-su-estabilidad-econ\%C3\%B3mica

Arancibia, Juan. (1993). El ajuste estructural en Centroamérica. En Carlos Vilas (Coord.), Democracia emergente en Centroamérica (pp. 33-50). México:

Centro de Investigaciones Interdisciplinarias en Ciencias y Humanidades (CEIICH)-Universidad Nacional Autónoma de México (UNAM).

Arévalo Cuadra, Raúl. (2007). iAlto al fuego! La experiencia de la Brigada Especial de Desarme (BED). Nicaragua: Instituto de Investigaciones y Acción Social Martín Luther King-Universidad Politécnica de Nicaragua.

Asamblea Nacional. (14 de junio de 2013). Ley Número 840. Ley especial para el desarrollo de infraestructura y transporte nicaragüense Atingente a el Canal, Zonas de Libre Comercio e Infraestructuras Asociadas. La Gaceta Diario Oficial, No. 110.

Barrios de Chamorro, Violeta. (1996). Memorias de mi gobierno 1990-1996. Managua: Gobierno de la República de Nicaragua, Dirección de Comunicación Social de la Presidencia.

Bartra, Armando. (2016). Las milpas de la ira. "En este mundo cabrón, quien no resiste no existe". México: Bartra.

CEPAL. (2002). Centroamérica: el impacto de la caída de los precios del café. México: Comisión Económica para América Latina.
CEPAL. (2018). La inversión extranjera directa en América Latina y el Caribe. México: Comisión Económica para América Latina.

CIAV-OEA. (1998). La desmovilización y reinserción de la Resistencia Nicaragüense. Estados Unidos: CIAV-OEA.

Close, David. (2005). Los años de doña Violeta. La historia de la transición política. Nicaragua: Lea Grupo Editorial.

Combates en la zona norte. Tres Recontras muertos en Llanos del Colón (8 de enero de 1993). El Nuevo Diario, p. 8.

Descolectivización: Reforma Agraria. (Noviembre de 1994). Envío. Información sobre Nicaragua y Centroamérica, 154. Recuperado de http:// www.envio.org.ni/articulo/899

Embajada de Estados Unidos en Nicaragua. (2011). Tratado de Libre Comercio entre Estados Unidos, América Central y República Dominicana.

En el vórtice de otro huracán: la corrupción. (Abril de 1999). Envío. Información sobre Nicaragua y Centroamérica, 204.

Enríquez, Laura. (1993). La reforma agraria en Nicaragua: pasado y futuro. En Carlos Vilas (Coord.), Democracia emergente en Centroamérica (pp. 123-159). México: Centro de Investigaciones Interdisciplinarias en Ciencias y Humanidades (CEIICH)-Universidad Nacional Autónoma de México (UNAM).

FMI da detalles de la deuda condonada. (22 de diciembre de 2005). El Nuevo Diario, p. 1. Geert van del Post, Jan. (2014). El largo y sinuoso camino. Razones por las que no ha sido construido el Canal de Nicaragua. Managua: Instituto de Historia de Nicaragua y Centroamérica (IHNCA).

Geert van del Post, Jan. (2014). El largo y sinuoso camino. Razones por las que no ha sido construido el Canal de Nicaragua. Managua: Instituto de Historia de Nicaragua y Centroamérica 
(IHNCA). Gobierno entrega extensos bosques. Compañía

López Baltodano, Mónica. (2015). Sueño y catástrofe. Lo que debemos saber sobre el proyecto del gran canal interoceánico en Nicaragua. Managua: Popol Na-Grupo Cocibolca.

Monroy García, Juan. (2001). Transición a la democracia en Nicaragua 1990-1996. México: uaem/ ccydel-unam.

Morales Carazo, Jaime. (1989). La Contra. Anatomía de una múltiple traición. México: Editorial Planeta.

Núñez Soto, Orlando y Cardenal, Gloria. (1992). La guerra y el campesinado en Nicaragua. Managua: CIPRES.

OCMAL. (2016). Proyecto Pavón, Observatorio de Conflictos Mineros en América Latina. Recuperado de https://mapa.conflictosmineros.net/ocmal_ db-v2/proyecto/view/524

Privatización: tres puntos de vista. (Octubre de 1991). Envío. Información sobre Nicaragua y Centroamérica, 120. Recuperado de http://www. envio.org.ni/articulo/688

Rearmados en el Triángulo Minero. (Junio de 1999). Envío. Información sobre Nicaragua y Centroamérica, 291. Recuperado de http://www. envio.org.ni/articulo/2356

Regeneración Radio. (2016). Nicaragua. Despojo y ausencia de soberanía: la tierra prometida. Regeneración Radio. Recuperado de www.regeneracionradio.org/index.php/represion/

despojo/item/4703-nicaragua-despojo-y-ausencia-de-soberania-la-tierraprometida
Rueda Estrada, Verónica. (2013). El Campesinado migrante. Políticas agrarias, colonizaciones internas y movimientos de frontera agrícola en Nicaragua 1960-2012. Tzintzun, Revista de Estudios Históricos, 57, 155-198.

Rueda Estrada, Verónica. (2015). Recompas, recontras, revueltos y rearmados. Posguerra y conflictos por la tierra en Nicaragua. México: Instituto Mora-UNAM.

Sánchez González, Mario. (2016). Los recursos en disputa. El caso del conflicto minero en Rancho Grande, Nicaragua. Anuario de Estudios Centroamericanos, 42(1), 93-131. Recuperado de https://

revistas.ucr.ac.cr/index.php/anuario/article/ view/26939

UNOs contra UNOs: Región V en rebelión (Diciembre de 1990). Envío. Información sobre Nicaragua y Centroamérica, 110. Recuperado de http:// www.envio.org.ni/articulo/647

Vilas, Carlos (1991). El debate interno sandinista. Nueva Sociedad, 113, 28-36. Recuperado de http:// nuso.org/media/articles/downloads/1992_1.pdf

Vilas, Carlos. (1993). Democracia emergente en Centroamérica. México: Centro de Investigaciones Interdisciplinarias en Ciencias y Humanidades (CEIICH)-Universidad Nacional Autónoma de México (UNAM).

Vilas, Carlos. (1994). Mercado, estados y revoluciones. Centroamérica 1950-1990. México: Centro de

Licenciado en Historia con mención en arqueología. Máster en Antropología y Liderazgo Social. Presidente de la Fundación Científica Cultural Ulúa Matagalpa y Asesor cultural del Pueblo Indígena Matagalpa. Se ha desempeñado como investigador de la Fundación Ulúa Matagalpa, además de fungir como asesor cultural del Pueblo Indígena Matagalpa. Docente Horario de la UNAN FAREN Matagalpa. 